\title{
Choledochal cyst a case report
}

\section{Summary}

The choledochal cyst is a rare disease of unknown etiology, most prevalent in childhood, however, occurs in $20 \%$ of adult patients. Also, it is associated with a hepatobiliary disease. A case of an 18 year-old patient, with a recurrent abdominal pain, was diagnosed with the performance of an abdominal ultrasound and the Magnetic Resonance Image. After that, the surgical procedure was the resection of the lesion with an open technique without postoperative complications and with an adequate and definitive evolution of the clinical presentation.

Keywords: choledochal cyst, recurrent abdominal pain, treatment
Volume 4 Issue I - 2017

\author{
Arévalo C,' Zurita N,' Borraez B² \\ 'Department of Surgery, Sinú University, Colombia \\ 2Department of Gastrointestinal Surgery, Oncology National \\ Institute, Colombia
}

\author{
Correspondence: Caterin Arévalo, Physician Surgeon, \\ Department of Surgery, Clinica Cartagena del Mar, Sinú \\ University, Street 2a \# 65 - 137, Crespo - Cartagena de Indias, \\ Colombia, Tel 3108688980, Fax 3419353, \\ Email cate-90@hotmail.com
}

Received: August 07, 2017 | Published: August 18,2017

\section{Introduction}

The choledochal cyst is defined as the congenital or combined dilatation of the extrahepatic biliary tree. It is observed in children and adults, predominantly in women. His previous approach was to perform an anastomosis between the cyst and the intestine, but a complete resection of the cyst should be performed in order to reduce the risk of malignancy and development of complications. We present the case of an 18year old man with recurrent abdominal pain secondary to this pathology, who underwent a surgical resection with primary anastomosis. He had a satisfactory postoperative with antibiotic treatment. The choledochal cyst as an uncommon pathology should always be considered in the differential diagnosis of those young patients with recurrent abdominal pain.

\section{Clinical case}

An 18year-old man who frequently went to the general medical service with generalized abdominal pain, which was treated with medication without results. The abdominal ultrasound evidenced according to the Todani classification a choledochal cyst type I. The Magnetic Resonance Cholangiopancreatography (Figure 1) confirming the presence of cystic dilatation of the biliary tract.

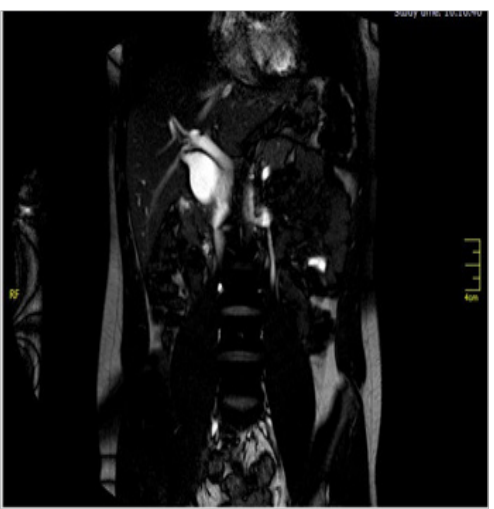

Figure I Confirming the presence of cystic dilatation of the biliary tract.

The patient denied another symptomatology. No personal or family history. The physical exploration was insubstantial without any masses or megalias. The analytical laboratories did not show any alterations except for the elevation of the level of the DHL. The patient was scheduled to perform a choledochal cyst resection (Figure
2) and Billroth II reconstruction, previous preoperative and adequate preanesthetic evaluation.

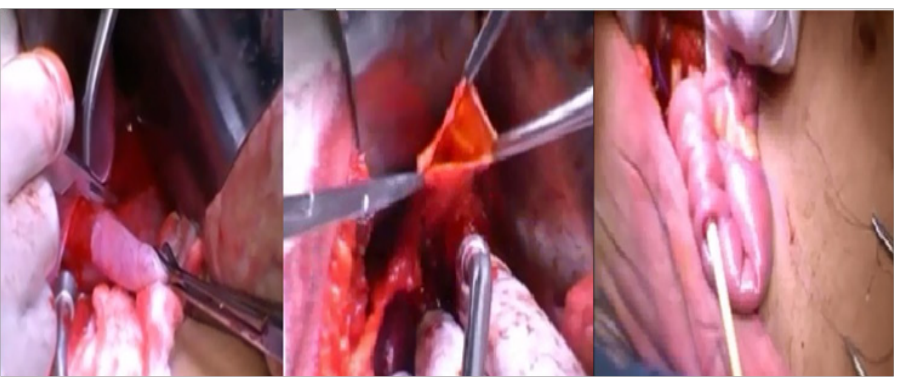

Figure 2 Open surgery: Complete resection of the choledochal cyst and T-tube placement.

Once was intervened, the evolution was satisfactorily, without complications, discharged on postoperative day 7. At the remote control three weeks after surgery, he presented persistent abdominal pain and unquantified fever. He was admitted to the ER and they decided to transfuse for anemia and to take liver function tests which are elevated. They left him in observation and abdominal computed tomography was realised which does not show changes. The patient progresses favorably with adequate hemodynamic stability, with total improvement and withdrawal of the T-tube, normal liver tests and subsequent return to normal life (Figure 3).

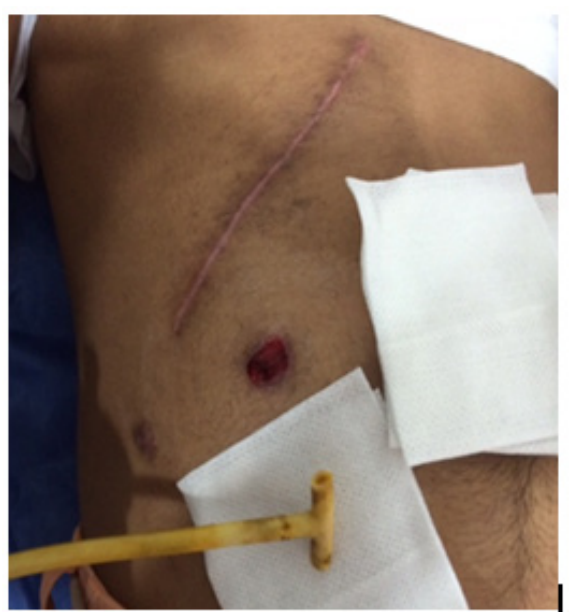

Figure 3 Adequate postoperative evolution. T-tube removal. 


\section{Discussion}

Choledochal cyst is a disease of the biliary tract that can manifest throughout the biliary tree, frequently accompanying an abnormality of the pancreatic and biliar junction. ${ }^{1}$ In 1959 the first classification was made in three varieties, and then in 1977, Todani did so considering the intrahepatic compromise of the same, reclassifying them in 5 types. $^{2}$

In 1991, Serena Serradel, modified this classification as: Type I cysts or spinal dissection of the common bile duct. ${ }^{3}$ Type II or diverticularly. Type III or choledococele are intraduodenal or intrapancreatic, and are subdivided into variants according to their origin. ${ }^{4}$ Type IV, representing a multicystic variety subdivided into variant $A$, with intra and extrahepatic compromise, and variant $\mathrm{B}$, confined to the extrahepatic biliary tract. Type V or Caroli syndrome, ${ }^{5}$ and Type VI, corresponds to cystic dilatation of the cystic duct (Figure 4).

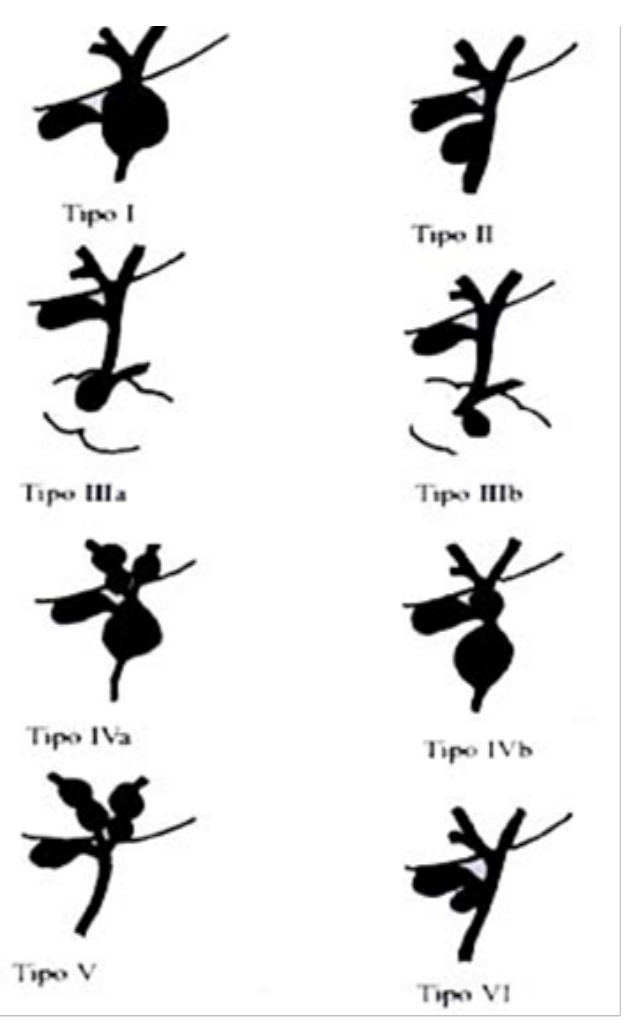

Figure 4 Modified todani classification of choledochal cysts.

It is characterized by a rare congenital anomaly of the bile duct that may be associated with complications such as infections, obstructions and neoplasm's. For that reason, a complete resection of the cyst should be made close to the diagnosis. The ultrasound usually makes the diagnosis and gives the information regarding the size and the characteristics of the involved ducts. Data is relevant for surgery. The Magnetic Resonance, on the other hand, has an important role in the assessment of biliary tract in adults and even in children, and has demonstrated its use in congenital pathologies of the bile duct.

The Magnetic Resonance is an effective and non-invasive technique for the study of the bile duct. The certain diagnostic has been reported close to $100 \%$. Given the development of new technologies it is possible to obtain high-quality images in patients. ${ }^{6}$

There are three specific varieties of these cysts, among which are mentioned a dilatation of the entire bile duct and the common hepatic duct, in which the cystic enters to the cyst; A small cyst located in the distal portion of the common bile duct and a fusiform dilatation of the common bile duct. The most common is type I. ${ }^{7}$ It is associated with anomalous union of the pancreatic and bile duct, stenosis of the distal portion of the common bile duct and dilation of the intrahepatic ducts.

The diagnosis is confused with benign disease of the pancreas or biliary tract. Complications include cholangitis, jaundice, pancreatitis, portal hypertension and cholangiocarcinoma. ${ }^{8}$ Previously, cystoenteroanastomosis was approached for these cysts, but it is now recommended to perform a complete excision of the cyst to reduce the risk of malignancy and development of recurrent cholangitis or pancreatitis. $^{9}$ After an appropriate digestive biliary bypass, intrahepatic dilatation tends to decrease in caliber in the postoperative period without complications. ${ }^{10}$

\section{Results}

Our current experience allows us to show the correct evolution of the pre and postoperative of an 18year old patient with a diagnosis of a rare pathology, obtaining favorable results that improve the clinical picture favorably.

\section{Conclusion}

A safe, open and conventional method of a complete resection of the choledochal cyst is demonstrated in a case with rare presentation pathology and obtaining very good results, without complications.

\section{Acknowledgements}

None.

\section{Conflict of interest}

Author declares that there is no conflict of interest.

\section{References}

1. Todani T, Watanabe Y, Toki A, et al. Clssification of congenital biliary cystic disease: special reference to type IC and IVA cyst with primary ductal stricture. J Hepatobiliary Pancreat Surg. 2003;10(5):430-444.

2. Todani T, Watanabe $\mathrm{Y}$, Narusue M, et al. Congenital bile duct cyst: Classification, operative procedures, review of 37 cases including cancer arising from choledochal cyst. Am J Surg. 1977;134(2):139-169.

3. Chaudhary A, Dhar P, Sachdev A, et al. Choledochal cysts- differences in children and adults. Br J Surg. 1996;83(2):186-188.

4. O’Neill JA. Choledochal Cyst. Curr Probl Surg. 1992;29(6):363-410.

5. Serrano M GE, Contreras J. Sín-drome de Caroli. Rev Colomb Cir. 1993;8(3):203-206.

6. Ortega XF. Radiologic Clinic Case: Choledocal Cyst. Rev Med Clin Condes. 2009;20(6):911-914.

7. Schwartz SI. Principios de cirugía. Mexico; 2000.

8. Weyant MD, Michael J. The Choledochal Cysts in adults. Am J Gastroenterol. 1998;93(11):2580-2583.

9. Laura Arroyo-Martínez, Royner Montero-Carvajal, José Ayi-Wong. Quiste del colédoco como causa de dolor abdominal: Revisión de un caso y bibliografía. Acta Med Costarric. 2004;46(3):145-154.

10. Lenriot JP, Gigot JF, Ségol P, et al. Bile duct cyst in adults. A multi institutional retrospective study. Ann Surg. 1998;228(2):159-166. 